\title{
Optimal Wire Myography Normalization for the Rat Dorsal Penile, Internal Pudendal and Internal Iliac Arteries
}

\author{
Tooyib A. AZEEZ ${ }^{1}$, Manuella R. ANDRADE ${ }^{1}$, Justin D. LA FAVOR ${ }^{1}$ \\ ${ }^{1}$ Department of Nutrition and Integrative Physiology, Florida State University, Tallahassee, Florida, \\ U.S.A.
}

Received April 26, 2021

Accepted August 31, 2021

Epub Ahead of Print October 30, 2021

\section{Summary}

In functional arterial studies using wire myography, the determination of a vessel's standardized normalization factor (factor k) is an essential step to ensure optimal contraction and relaxation by the arteries when stimulated with their respective vasoactive agents and to obtain reproducible results. The optimal factor $\mathrm{k}$ for several arteries have been determined, however, the optimal initial tension and factor $\mathrm{k}$ for the arteries involved in erection remains unknown. Hence, in the present study we set out to determine the optimal factor $\mathrm{k}$ for the internal iliac artery, proximal and distal internal pudendal artery (IPA), and dorsal penile artery. After isolating, harvesting, and mounting the arteries from male Sprague-Dawley rats on a multi wire myograph, we tested arterial responsivity to high $\mathrm{K}^{+}$-stimulation when the factor $\mathrm{k}$ was set at $0.7,0.8,0.85,0.9,0.95,1.0,1.1$, and 1.2 to determine the factor $\mathrm{k}$ setting that results in the greatest $\mathrm{K}^{+}$-induced active force production for each vessel type. The data showed the optimal factor $k$ is $0.90-0.95$ for the dorsal penile, distal internal pudendal and internal iliac arteries while it is $0.85-0.90$ for proximal internal pudendal artery. These optimal values corresponded to initial passive tension settings of $1.10 \pm 0.16-1.46 \pm 0.23,1.28 \pm 0.20-1.69 \pm 0.34,1.03 \pm 0.27-$ $1.33 \pm 0.31$, and $1.33 \pm 0.31-1.77 \pm 0.43 \mathrm{mN} / \mathrm{mm}$ for the dorsal penile, distal IP, proximal IP, and internal iliac arteries, respectively.
\end{abstract}

\section{Key words}

Normalization procedure - Optimal initial tension - Myograph • Pre-penile arteries • Erectile dysfunction

\section{Corresponding author}

Justin D. La Favor, 107 Chieftan Way, Tallahassee, FL 32306, USA. Email: jlafavor@fsu.edu
Erectile dysfunction is the loss of the ability to attain and sustain an erect penis necessary for optimal sexual performance, affecting a significant number of men at least once in their lifetime (Yafi et al. 2016). Penile erection is largely a vascular event that requires an intact endothelial lining of arteries as well as nerves that supply the penis (Contreras et al. 2013). Internal pudendal arteries (IPA) which are the main source of blood to the penis, originate from the internal iliac arteries and terminate as dorsal and deep arteries of the penis (Odom et al. 2017). The concurrent increase in arterial blood flow via arterial dilation and erectile smooth muscle relaxation coupled with occlusion of subtunical venules lead to accumulation of blood in the sinusoidal space giving rise to erection (Giuliano 2011). Erectile function has traditionally been assessed in rodent models by measuring changes in intracavernous pressure in response to electrical stimulation of the cavernous nerve (Burnett et al. 1992). However, ex vivo functional assessment of the arteries that supply blood to the penis can provide insight into the mechanistic basis of the vascular component of erectile dysfunction. A wire myograph system can be utilized for such studies investigating vascular reactivity to various vasoconstrictor and vasodilatory agents, enzymatic inhibitors, or other vasoactive stimuli (Mulvany \& Halpern 1977).

Normalization is an essential step of wiremyography that involves setting the internal circumference of the vessel to that which produces the maximal isometric contractility (Mulvany \& Warshaw

PHYSIOLOGICAL RESEARCH • ISSN 1802-9973 (online) - an open access article under the CC BY-NC-ND 4.0 license (C) 2021 Institute of Physiology of the Czech Academy of Sciences, Prague, Czech Republic 
1979). It is known that vascular reactivity depends on the initial tension of the vessels (Ping et al. 2014), making this step of great importance for accurate comparison of drug effects and reproducibility of results (Slezák et al. 2010). The normalization process is typically performed by testing the length-tension relationship of each vessel segment. For most resistance arteries, the internal circumference corresponding to a transmural pressure of $100 \mathrm{mmHg}\left(\mathrm{IC}_{100}\right)$ is sought. The $\mathrm{IC}_{100}$ is then multiplied by a normalization factor, the factor $\mathrm{k}$, to determine the optimal internal circumference $\left(\mathrm{IC}_{1}\right)$ for each segment to produce maximal vascular reactivity. The jaws of the myograph system are then adjusted to the diameter corresponding to the $\mathrm{IC}_{1}$, at which the vessel segments remain for physiological experimentation. The optimal factor $\mathrm{k}$ varies across the vascular tree and is thus important to establish prior to experimentation for each artery type. The optimal factor $\mathrm{k}$ has been determined for rat mesenteric, femoral, basilar, and coronary arteries (Zhang et al. 2007, Slezák et al. 2010, Ping et al. 2014, Xiao et al. 2015, Sun et al. 2018). However, this value remains unknown for the arteries involved in the erection process. We will therefore experimentally determine the optimal factor $\mathrm{k}$ for the dorsal penile artery, distal IPA, proximal IPA, and internal iliac artery.

Twelve young-adult (12-14 weeks) male Sprague-Dawley rats (325-350 g) were obtained from Charles River Laboratories (Wilmington, MA). The protocol was approved by the animal care and use committee of Florida State University. Rats were anesthetized using an intraperitoneal injection of ketamine $(90 \mathrm{mg} / \mathrm{kg})$ with xylazine $(10 \mathrm{mg} / \mathrm{kg})$ and euthanized by exsanguination and double pneumothorax. The rats were placed in the supine position, and a supra pubic horizontal incision was made to expose the penis. The abdominal wall was then lifted, and a vertical incision was made to expose the pubic symphysis and the abdominal contents. The pubic symphysis was bisected, the descending and ascending limbs of pubis were also cut to expose the distal end of the pudendal bundle. The bladder and testes were reflected upwards, and the rectum was cut at the level of the superior border of pubis. The rectus abdominis, caudal flexors and the distal heads of iliacus, psoas major, quadratus lumborum and obliquus internus were cut to expose the IPA and the internal iliac artery at the point where it branches off from the common iliac artery. After clearing the muscles and ligaments, we were able to trace the dorsal penile artery to the IPA, then to the internal iliac artery and finally to the common iliac artery. The dorsal penile artery was harvested from the point of bifurcation of the IPA into the dorsal penile and deep penile arteries, and at the point where the dorsal penile artery enters the penis. The IPA was divided into proximal (between the internal iliac and $1 \mathrm{~mm}$ proximal to the bifurcation of the gluteal artery) and distal IPA which is $1 \mathrm{~mm}$ distal to the gluteal artery bifurcation to the point where the IPA terminates by dividing into dorsal and deep penile arteries (Odom et al. 2017). The arteries were harvested and immersed into oxygenated ice-cold Kreb's buffer $(\mathrm{NaCl} 130 \mathrm{mM}, \mathrm{KCl} 4.7 \mathrm{mM}$, $\mathrm{KH}_{2} \mathrm{PO}_{4} 1.18 \mathrm{mM}, \mathrm{MgSO}_{4} 1.18 \mathrm{mM}, \mathrm{NaHCO}_{3} 14.9 \mathrm{mM}$, D-Glucose 5.6mM, $\mathrm{CaCl}_{2} 1.56 \mathrm{mM}$ and EDTA $0.03 \mathrm{mM}$ ). The vessels were cleaned of connective tissues and cut into 1-2 mm segments. One segment from the right and left side of the body of each rat of each artery type was used. A $40 \mu \mathrm{m}$-diameter stainless steel wire was passed through each segment and used to mount to the jaw of the myograph (Multi wire myograph system 620M, Danish Myotechnology A/S, Aarhus, Denmark), which is connected to a micrometer used to adjust the distance between the two jaws. A second $40 \mu \mathrm{m}$ wire was then passed into the artery and connected to the second jaw which is connected to a force transducer. The vessels were maintained at $37^{\circ} \mathrm{C}$ in Kreb's solution and continuously perfused with a $95 \% \mathrm{O}_{2}, 5 \% \mathrm{CO}_{2}$ gas mixture and then left to equilibrate for 1 hour while the Kreb's solution was changed every $15 \mathrm{~min}$.

Following equilibration, incremental tension was applied by gradually increasing the diameter of the vessels. The micrometer settings and passive tension at the incremental diameters were recorded, and the effective pressure was calculated by the DMT Normalization software (LabChartPro, ADInstruments) using La Place's Law. Steps were added until the effective pressure exceeded $100 \mathrm{mmHg}$. The internal circumference of each vessel segment was then adjusted to correspond to a factor $\mathrm{k}$ of 0.7 , and the vessels were allowed to equilibrate for $45 \mathrm{~min}$ with changes in Kreb's solution every $15 \mathrm{~min}$. The vessel segments were then challenged for $15 \mathrm{~min}$ with high-K $\mathrm{K}^{+}(120 \mathrm{mM})$ Kreb's solution, with $\mathrm{KCl}$ substituted for $\mathrm{NaCl}$. Vessels were washed for $5 \mathrm{~min}$ with $\mathrm{Ca}^{2+}$-free Kreb's solution to rapidly restore passive tension to pre-high- $\mathrm{K}^{+}$levels. The bath was replaced with Kreb's solution and allowed to stabilize at the pre-high- $\mathrm{K}^{+}$passive tension level before the internal diameters were adjusted to correspond to a 0.8 factor $\mathrm{k}$. The vessels were allowed to equilibrate for $30 \mathrm{~min}$ at the new diameter setting. The process of high- 
$\mathrm{K}^{+}$challenge, $\mathrm{Ca}^{2+}$-free solution washout, and internal diameter adjustment was repeated for factors $\mathrm{k}$ of 0.85 , $0.90,0.95,1.00,1.10$, and 1.20. The data were continuously recorded using LabChart v8 software (AD Instruments, Dunedin, New Zealand). Passive tension was recorded as the mean tension over one minute prior to the high- $\mathrm{K}^{+}$challenge. Peak tension was recorded as the mean tension over 30 seconds of maximal $\mathrm{K}^{+}$-induced constriction. Active tension was determined by subtracting passive tension from peak tension. Tension values were normalized to vessel length for comparative and statistical analysis by dividing the tension value $(\mathrm{mN})$ by $2 \mathrm{x}$ the length $(\mathrm{mm})$ of the vessel segment used (Mulvany \& Halpern 1977). The optimal factor k was defined as the setting which produced the greatest normalized active tension within each artery type. Vessel segments that produced peak active tension less than $1.5 \mathrm{mN} / \mathrm{mm}$ were excluded from the analysis.

Statistical analysis was performed using GraphPad Prism v8 (La Jolla, CA). One-way repeated measures ANOVA followed by Tukey's post-hoc test was used to determine differences in normalized active tension production across factor $\mathrm{k}$ settings within each artery type. Active force production from vessels from opposing body sides were compared at the optimal factor $\mathrm{k}$ setting for each respective artery type investigated using a paired t-test. The diameter of each vessel segment was recorded at the $\mathrm{IC}_{100}$ point for comparison of vessel diameters between body sides of the animal, for which a paired t-test was used to determine any potential differences in artery diameter between body side.
Statistical significance was set as $\mathrm{P}<0.05$ and all data were presented as Mean \pm SD.

The relationship between passive tension, $\mathrm{K}^{+}$-induced active tension, and diameter at each respective factor $\mathrm{k}$ setting of the rat pre-penile arteries are shown in Tables 1-4. Passive tension and $\mathrm{K}^{+}$-induced active tension are presented as total tension values $(\mathrm{mN})$ and as tension values normalized to the length of each artery segment used $(\mathrm{mN} / \mathrm{mm})$. For the four artery segments, the passive tension increases with increases in factor $\mathrm{k}$, while the increase in active tension plateaus at $\mathrm{k}=0.9$ for all the arteries, after which the active tension begins to decline. This pattern has been described in mesenteric, basilar, and coronary arteries (Ping et al. 2014, Xiao et al. 2015, Zhang et al. 2007), while a peak active tension at $\mathrm{k}=1.0$ with subsequent decline has been observed for the femoral artery (Slezák et al. 2010). The data suggest that the optimal factor $\mathrm{k}$ is $0.90-0.95$ for the dorsal penile, distal internal pudendal and internal iliac arteries while it is 0.85-0.90 for the proximal internal pudendal artery. These optimal factor $\mathrm{k}$ settings corresponded to initial passive tension settings of $1.10 \pm 0.16-1.46 \pm 0.23,1.28 \pm 0.20$ $1.69 \pm 0.34, \quad 1.03 \pm 0.27 \quad-1.33 \pm 0.31$, and $1.33 \pm 0.31 \quad-$ $1.77 \pm 0.43 \mathrm{mN} / \mathrm{mm}$ for the dorsal penile, distal IP, proximal IP, and internal iliac arteries, respectively. There were no significant differences in diameter or active tension between vessels from the left and right side of the body for any of the arteries investigated. These results are consistent with morphological homogeneity of the pre-penile vasculature between the right and left side of the body (Hannan et al. 2011).

Table 1. Relationship between passive tension, active tension, and vessel diameter at each respective factor $k$ setting of rat dorsal penile artery

\begin{tabular}{lccccc}
\hline Factor & Passive Tension & \multicolumn{2}{c}{ Dorsal Penile Artery } & Total Passive & Active Tension \\
$\mathbf{K}$ & $(\mathbf{m N} / \mathbf{m m})$ & Tension $(\mathbf{m N})$ & $\begin{array}{c}\text { Total Active } \\
(\mathbf{m N} / \mathbf{m m})\end{array}$ & $\begin{array}{c}\text { Diameter } \\
\text { Tension }(\mathbf{m N})\end{array}$ \\
\hline 0.70 & $0.39 \pm 0.08$ & $1.16 \pm 0.29$ & $1.90 \pm 0.44^{\dagger \dagger}$ & $5.72 \pm 1.52$ & $293 \pm 47$ \\
0.80 & $0.68 \pm 0.11$ & $2.04 \pm 0.50$ & $2.31 \pm 0.52^{\dagger}$ & $6.96 \pm 1.83$ & $335 \pm 53$ \\
0.85 & $0.85 \pm 0.13$ & $2.57 \pm 0.67$ & $2.50 \pm 0.54^{*}$ & $7.52 \pm 1.95$ & $356 \pm 57$ \\
0.90 & $1.10 \pm 0.16$ & $3.32 \pm 0.83$ & $2.59 \pm 0.56$ & $7.79 \pm 1.95$ & $377 \pm 60$ \\
0.95 & $1.46 \pm 0.23$ & $4.40 \pm 1.15$ & $2.53 \pm 0.53$ & $7.65 \pm 2.02$ & $398 \pm 63$ \\
1.00 & $1.96 \pm 0.34$ & $5.89 \pm 1.61$ & $2.40 \pm 0.49 *^{\dagger}$ & $7.26 \pm 2.00$ & $419 \pm 67$ \\
1.10 & $3.26 \pm 0.61$ & $9.87 \pm 3.07$ & $1.96 \pm 0.44 * \dagger$ & $6.23 \pm 2.10$ & $461 \pm 73$ \\
1.20 & $5.14 \pm 1.78$ & $15.17 \pm 4.77$ & $1.64 \pm 0.43 * *^{\dagger}$ & $5.38 \pm 2.37$ & $503 \pm 80$ \\
\hline
\end{tabular}

Passive and active tension values are presented as normalized to vessel segment length and as absolute (total) values. Data are presented as Mean \pm SD for $n=20$ artery segments from $N=11$ rats. ${ }^{*} P<0.05$, compared to factor $k=0.90,{ }^{+} P<0.05$, compared to factor $\mathrm{k}=0.95$. 
Table 2. Relationship between passive tension, active tension, and vessel diameter at each respective factor $k$ setting of rat distal IPA

\begin{tabular}{|c|c|c|c|c|c|}
\hline \multicolumn{6}{|c|}{ Distal Internal Pudendal Artery } \\
\hline $\begin{array}{l}\text { Factor } \\
\mathbf{K}\end{array}$ & $\begin{array}{l}\text { Passive Tension } \\
\qquad(\mathrm{mN} / \mathbf{m m})\end{array}$ & $\begin{array}{l}\text { Total Passive } \\
\text { Tension }(\mathrm{mN})\end{array}$ & $\begin{array}{c}\text { Active Tension } \\
\qquad(\mathrm{mN} / \mathbf{m m})\end{array}$ & $\begin{array}{c}\text { Total Active } \\
\text { Tension }(\mathbf{m N})\end{array}$ & $\begin{array}{l}\text { Diameter } \\
\qquad(\mu \mathrm{m})\end{array}$ \\
\hline 0.70 & $0.45 \pm 0.07$ & $1.67 \pm 0.35$ & $2.75 \pm 0.97 * \dagger$ & $10.34 \pm 4.05$ & $341 \pm 68$ \\
\hline 0.80 & $0.79 \pm 0.11$ & $2.93 \pm 0.58$ & $3.33 \pm 1.01 * \dagger$ & $12.51 \pm 4.31$ & $390 \pm 78$ \\
\hline 0.85 & $1.00 \pm 0.12$ & $3.73 \pm 0.71$ & $3.58 \pm 1.13^{*}$ & $13.47 \pm 4.81$ & $415 \pm 83$ \\
\hline 0.90 & $1.28 \pm 0.20$ & $4.78 \pm 1.06$ & $3.71 \pm 1.18$ & $13.94 \pm 5.04$ & $439 \pm 88$ \\
\hline 0.95 & $1.69 \pm 0.34$ & $6.35 \pm 1.63$ & $3.70 \pm 1.21$ & $13.92 \pm 5.15$ & $463 \pm 93$ \\
\hline 1.00 & $2.27 \pm 0.54$ & $8.53 \pm 2.48$ & $3.54 \pm 1.25^{* \dagger}$ & $13.32 \pm 5.27$ & $488 \pm 98$ \\
\hline 1.10 & $4.02 \pm 1.19$ & $15.16 \pm 5.29$ & $2.94 \pm 1.06^{* \dagger}$ & $11.05 \pm 4.45$ & $536 \pm 107$ \\
\hline 1.20 & $6.41 \pm 2.16$ & $24.18 \pm 9.02$ & $2.39 \pm 1.05^{\dagger \dagger}$ & $8.98 \pm 4.37$ & $585 \pm 117$ \\
\hline
\end{tabular}

Passive and active tension values are presented as normalized to vessel segment length and as absolute (total) values. Data are presented as Mean $\pm S D$ for $n=23$ artery segments from $N=12$ rats. ${ }^{*} P<0.05$, compared to factor $k=0.90,{ }^{\dagger} P<0.05$, compared to factor $\mathrm{k}=0.95$.

Table 3. Relationship between passive tension, active tension, and vessel diameter at each respective factor $k$ setting of rat proximal IPA

\begin{tabular}{|c|c|c|c|c|c|}
\hline \multicolumn{6}{|c|}{ Proximal Internal Pudendal Artery } \\
\hline $\begin{array}{l}\text { Factor } \\
\mathbf{K}\end{array}$ & $\begin{array}{l}\text { Passive Tension } \\
\qquad(\mathrm{mN} / \mathrm{mm})\end{array}$ & $\begin{array}{l}\text { Total Passive } \\
\text { Tension }(\mathrm{mN})\end{array}$ & $\begin{array}{c}\text { Active Tension } \\
(\mathbf{m N} / \mathbf{m m})\end{array}$ & $\begin{array}{c}\text { Total Active } \\
\text { Tension (mN) }\end{array}$ & $\begin{array}{c}\text { Diameter } \\
(\mu \mathrm{m})\end{array}$ \\
\hline 0.70 & $0.45 \pm 0.15$ & $1.58 \pm 0.62$ & $2.72 \pm 1.08 * *$ & $9.51 \pm 4.23$ & $364 \pm 76$ \\
\hline 0.80 & $0.80 \pm 0.22$ & $2.81 \pm 0.95$ & $3.34 \pm 1.28 * *$ & $11.65 \pm 5.08$ & $416 \pm 87$ \\
\hline 0.85 & $1.03 \pm 0.27$ & $3.60 \pm 1.19$ & $3.53 \pm 1.31$ & $12.39 \pm 5.31$ & $442 \pm 93$ \\
\hline 0.90 & $1.33 \pm 0.31$ & $4.64 \pm 1.42$ & $3.59 \pm 1.27$ & $12.59 \pm 5.18$ & $468 \pm 98$ \\
\hline 0.95 & $1.77 \pm 0.40$ & $6.17 \pm 1.81$ & $3.52 \pm 1.24^{*}$ & $12.34 \pm 5.05$ & $494 \pm 104$ \\
\hline 1.00 & $2.39 \pm 0.52$ & $8.30 \pm 2.29$ & $3.32 \pm 1.16^{*}$ & $11.66 \pm 4.81$ & $520 \pm 109$ \\
\hline 1.10 & $4.41 \pm 1.17$ & $15.34 \pm 4.87$ & $2.66 \pm 0.94 * t$ & $9.38 \pm 3.95$ & $572 \pm 120$ \\
\hline 1.20 & $6.89 \pm 2.13$ & $23.95 \pm 8.42$ & $2.16 \pm 0.84 * *$ & $7.64 \pm 3.52$ & $623 \pm 131$ \\
\hline
\end{tabular}

Passive and active tension values are presented as normalized to vessel segment length and as absolute (total) values. Data are presented as Mean $\pm S D$ for $n=23$ artery segments from $N=12$ rats. $* P<0.05$, compared to factor $k=0.90,{ }^{\ddagger} \mathrm{P}<0.05$, compared to factor $\mathrm{k}=0.85$.

Several functional studies involving penile arteries (Villalba et al. 2007, Sánchez et al. 2008, 2012, Grann et al. 2016) have been performed with factor $\mathrm{k}$ set to 0.9 , which is consistent with our finding. Studies utilizing wire myography to investigate the IPA have varied far more across the field in their approach to normalization. One study involving the IPA has used a factor $\mathrm{k}$ of 0.9 (Silva et al. 2019). Another study reported that the vessels were stretched to a passive tension of $3 \mathrm{mN}$ for $3 \mathrm{~mm}$ vessel segments (Rodrigues et al. 2016), which is similar to the $1.03-1.69 \mathrm{mN} / \mathrm{mm}$ of passive tension that we observed to be optimal. Similarly, another study has used 1.2-1.5 mN of passive tension for $2 \mathrm{~mm}$ segments of the IPA (Hannan et al. 2010). Several investigations have not specified the normalization parameters or passive tension settings used in their studies (Alves-Lopes et al. 2016, Kassan et al. 2013, Odom et al. 2017). Furthermore, studies utilizing the IPA (Alves-Lopes et al. 2016, Kassan et al. 2013, Rodrigues et al. 2016, Silva et al. 2019) rarely differentiate between the distal and proximal segments of the artery. However, we observed a slightly different optimal range of factor $\mathrm{k}$ values between the distal and proximal segments of the IPA. Odom et al reported markedly greater electrical field stimulation-mediated contraction and NO-dependent non-adrenergic non-cholinergic mediated relaxation in the distal IPA compared to the proximal IPA, while regional differences in purinergic vasoreactivity were also apparent (Odom et al. 2017). 
Table 4. Relationship between passive tension, active tension, and vessel diameter at each respective factor $k$ setting of rat internal iliac artery

\begin{tabular}{lccccc}
\hline Factor & $\begin{array}{c}\text { Passive Tension } \\
\mathbf{K}\end{array}$ & $\begin{array}{c}\text { Total Passive } \\
\text { Tension }(\mathbf{m} \mathbf{N})\end{array}$ & $\begin{array}{c}\text { Active Tension } \\
(\mathbf{m} \mathbf{m} / \mathbf{m m})\end{array}$ & $\begin{array}{c}\text { Total Active } \\
\text { Tension }(\mathbf{m N})\end{array}$ & $\begin{array}{c}\text { Diameter } \\
(\boldsymbol{\mu m})\end{array}$ \\
\hline 0.70 & $0.41 \pm 0.13$ & $1.52 \pm 0.52$ & $2.63 \pm 1.16^{* \dagger}$ & $9.92 \pm 5.04$ & $344 \pm 77$ \\
0.80 & $0.80 \pm 0.17$ & $2.96 \pm 0.75$ & $3.10 \pm 1.12^{* \dagger}$ & $11.47 \pm 4.62$ & $394 \pm 88$ \\
0.85 & $1.04 \pm 0.25$ & $3.83 \pm 1.10$ & $3.31 \pm 1.09^{*}$ & $12.21 \pm 4.55$ & $418 \pm 94$ \\
0.90 & $1.33 \pm 0.31$ & $4.90 \pm 1.34$ & $3.40 \pm 1.07$ & $12.54 \pm 4.49$ & $443 \pm 99$ \\
0.95 & $1.77 \pm 0.43$ & $6.53 \pm 1.80$ & $3.37 \pm 1.02$ & $12.41 \pm 4.25$ & $468 \pm 105$ \\
1.00 & $2.35 \pm 0.64$ & $8.65 \pm 2.56$ & $3.24 \pm 1.02 \dagger$ & $11.96 \pm 4.21$ & $492 \pm 110$ \\
1.10 & $3.99 \pm 1.27$ & $15.11 \pm 5.06$ & $2.74 \pm 0.86^{* \dagger}$ & $10.08 \pm 3.53$ & $541 \pm 121$ \\
1.20 & $6.03 \pm 2.15$ & $22.56 \pm 8.16$ & $2.23 \pm 0.73^{* \dagger}$ & $8.18 \pm 2.94$ & $590 \pm 132$ \\
\hline
\end{tabular}

Passive and active tension values are presented as normalized to vessel segment length and as absolute (total) values. Data are presented as Mean $\pm S D$ for $n=23$ artery segments from $N=12$ rats. ${ }^{*} P<0.05$, compared to factor $k=0.90,{ }^{\dagger} P<0.05$, compared to factor $\mathrm{k}=0.95$.

The distal IPA has also been shown to exhibit a smaller lumen diameter and increased wall thickness relative to the proximal IPA in healthy rats, as well as an increased susceptibility to calcification in models of chronic kidney disease (Maio et al. 2014). These differences highlight the need to control for anatomic region when performing functional assessment of these arteries.

In conclusion, the optimal factor $\mathrm{k}$ is $0.90-0.95$ for the dorsal penile, distal internal pudendal and internal iliac arteries, while it is $0.85-0.90$ for the proximal internal pudendal artery. The relationships between passive and active tension for ex vivo physiological testing of these arteries are presented to serve as a guide for new users and for those in which determining the IC100 is not feasible.

\section{Conflict of Interest}

There is no conflict of interest.

\section{Acknowledgements}

This study was supported by startup funds from Florida State University. J.D. La Favor is supported by the National Institutes of Health (NIH/NIDDK) Grant K01DK115540.

\section{References}

ALVES-LOPES R, NEVES KB, SILVA MAB, OLIVON VC, RUGINSK SG, ANTUNES-RODRIGUES J, RAMALHO LNZ, TOSTES RC, CARNEIRO FS: Functional and structural changes in internal pudendal arteries underlie erectile dysfunction induced by androgen deprivation. Asian J Androl 18: 526-532, 2016. https://doi.org/10.4103/1008-682X.173935

BURNETT AL, LOWENSTEIN CJ, BREDT DS, CHANG TSK, SNYDER SH: Nitric oxide: A physiologic mediator of penile erection. Science 257: 401-403, 1992. https://doi.org/10.1126/science.1378650

CONTRERAS C, SÁNCHEZ A, MARTÍNEZ P, CLIMENT B, BENEDITO S, GARCÍA-SACRISTÁN A, HERNÁNDEZ M, PRIETO D: Impaired endothelin calcium signaling coupled to endothelin type b receptors in penile arteries from insulin-resistant obese Zucker rats. J Sex Med 10: 2141-2153, 2013. https://doi.org/10.1111/jsm.12234

GIULIANO F: Neurophysiology of Erection and Ejaculation. $\quad \mathrm{J}$ Sex Med 8: 310-315, 2011. https://doi.org/10.1111/j.1743-6109.2011.02450.x

GRANN M, COMERMA-STEFFENSEN S, ARCANJO DDR, SIMONSEN U: Mechanisms Involved in Thromboxane A2 -induced Vasoconstriction of Rat Intracavernous Small Penile Arteries. Basic Clinical Pharmacol Toxicol 119: 86-95, 2016. https://doi.org/10.1111/bcpt.12544 
HANNAN JL, BLASER MC, PANG JJ, ADAMS SM, PANG SC, ADAMS MA: Impact of hypertension, aging, and antihypertensive treatment on the morphology of the pudendal artery. J Sex Med 8: 1027-1038, 2011. https://doi.org/10.1111/j.1743-6109.2010.02191.x

HANNAN JL, BLASER MC, OLDFIELD L, PANG JJ, ADAMS SM, PANG SC, ADAMS MA: Morphological and functional evidence for the contribution of the pudendal artery in aging-induced erectile dysfunction. J Sex Med 7: 3373-3384, 2010. https://doi.org/10.1111/j.1743-6109.2010.01920.x

KASSAN M, LASKER GF, SIKKA SC, MANDAVA SH, GOKCE A, MATROUGUI K, HELLSTROM WJG, KADOWITZ PJ, SEREFOGLU EC: Chronic escitalopram treatment induces erectile dysfunction by decreasing nitric oxide bioavailability mediated by increased nicotinamide adenine dinucleotide phosphate oxidase activity and reactive oxygen species production. Urology 82: 1188.e1-1188.e7, 2013. https://doi.org/10.1016/j.urology.2013.07.037

MAIO MT, MCCABE KM, PRUSS CM, PANG JJ, LAVERTY K, HOLDEN RM, ADAMS MA: Calcification of the internal pudendal artery and development of erectile dysfunction in adenine-induced chronic kidney disease: A sentinel of systemic vascular changes. J Sex Med 11: 2449-2465, 2014. https://doi.org/10.1111/jsm.12648

MULVANY MJ, HALPERN W: Contractile properties of small arterial resistance vessels in spontaneously hypertensive and normotensive rats. Circ Res 41: 19-26, 1977. https://doi.org/10.1161/01.RES.41.1.19

MULVANY MJ, WARSHAW DM: The active tension-length curve of vascular smooth muscle related to its cellular components. J Gen Physiol 74: 85-104, 1979. https://doi.org/10.1085/jgp.74.1.85

ODOM MR, PAK ES, BROWN DA, HANNAN JL: Enhanced electrical field stimulated nitrergic and purinergic vasoreactivity in distal vs proximal internal pudendal arteries. J Sex Med 14: 1285-1296, 2017. https://doi.org/10.1016/i.jsxm.2017.09.013

PING NN, CAO L, XIAO X, LI S, CAO YX: The determination of optimal initial tension in rat coronary artery using wire myography. Physiol Res 63: 143-146, 2014. https://doi.org/10.33549/physiolres.932631

RODRIGUES FL, LOPES RAM, FAIS RS, DE OLIVEIRA L, PRADO CM, TOSTES RC, CARNEIRO FS: Erectile dysfunction in heart failure rats is associated with increased neurogenic contractions in cavernous tissue and internal pudendal artery. Life Sci, 145: 9-18, 2016. https://doi.org/10.1016/j.lfs.2015.12.005

SÁNCHEZ A, VILlALBA N, MARTÍNEZ AC, GARCÍA-SACRISTÁN A, HERNÁNDEZ M, PRIETO D: Mechanisms of the relaxant effect of vardenafil in rat penile arteries. Eur J Pharmacol 586: 283-287, 2008. https://doi.org/10.1016/j.ejphar.2008.03.002

SÁNCHEZ A, CONTRERAS C, MARTÍNEZ MP, CLIMENT B, BENEDITO S, GARCÍA-SACRISTÁN A, HERNÁNDEZ M, PRIETO D: Role of neural no synthase (NNOS) uncoupling in the dysfunctional nitrergic vasorelaxation of penile arteries from insulin-resistant obese zucker rats. PLoS ONE 7: e36027, 2012. https://doi.org/10.1371/journal.pone.0036027

SILVA DF, WENCESLAU CF, MCCARTHY CG, SZASZ T, OGBI S, WEBB RC: TRPM8 channel activation triggers relaxation of pudendal artery with increased sensitivity in the hypertensive rats. Pharmacol Res 147: 104329, 2019. https://doi.org/10.1016/j.phrs.2019.104329

SLEZÁK P, WACZULÍKOVÁ I, BALIŠ P, PÚZSEROVÁ A: Accurate normalization factor for wire myography of rat femoral artery. Physiol Res 59: 1033-1036, 2010. https://doi.org/10.33549/physiolres.932043

SUN J, YANG GM, TAO T, WEI LS, PAN Y, ZHU MS: Isometric contractility measurement of the mouse mesenteric artery using wire myography. J Vis Exp 138: 58064, 2018. https://doi.org/10.3791/58064

VILLALBA N, STANKEVICIUS E, GARCIA-SACRISTÁN A, SIMONSEN U, PRIETO D: Contribution of both Ca ${ }^{2+}$ entry and $\mathrm{Ca}^{2+}$ sensitization to the $\alpha 1$-adrenergic vasoconstriction of rat penile small arteries. Am $\mathrm{J}$ Physiol Heart Circ Physiol 292: H1 157-1169, 2007. https://doi.org/10.1152/ajpheart.01034.2006

XIAO X, PING NN, LI S, CAO L, CAO YX: An optimal initial tension for rat basilar artery in wire myography. Microvasc Res 97: 156-158, 2015. https://doi.org/10.1016/j.mvr.2014.11.001

YAFI FA, JENKINS L, ALBERSEN M, CORONA G, ISIDORI AM, GOLDFARB S, MAGGI M, NELSON CJ, PARISH S, SALONIA A, TAN R, MULHALL JP, HELLSTROM WJG: Erectile dysfunction. Nat Rev Dis Prim 2: 16003, 2016. https://doi.org/10.1038/nrdp.2016.3 
ZHANG RZ, GASHEV AA, ZAWIEJA DC, DAVIS MJ: Length-tension relationships of small arteries, veins, and lymphatics from the rat mesenteric microcirculation. Am J Physiol Heart Circ Physiol 292: H1943-1952, 2007. https://doi.org/10.1152/ajpheart.01000.2005 